\title{
最近の鼻腔通気度表現法の比較について
}

\author{
内藤 健晴・岩田 重信・妹尾 淑郎・戸田 均 \\ 近藤 正道 $\cdot$ 大岡英太郎・近藤 由香 $\cdot$ 竹内 昌宏
}

\section{A Comparison of Current Expressions of Nasal Patency}

\author{
Kensei Naito, Shigenobu Iwata, Yoshio Senoo, Hitoshi Toda, \\ Masamichi Kondoh, Eitaro Ohoka, Yuka Kondoh \\ and Masahiro Takeuchi
}

(Fujita Health University School of Medicine)

\begin{abstract}
Rhinomanometry is well established as a useful clinical method for objective assessment of nasal patency. However, several expressions of nasal patency have been reported and complete standardization has never been accomplished.

In this report, nasal resistances calculated from the equation $\mathrm{R}=\Delta \mathrm{P} / \dot{\mathrm{V}}$ at $\Delta \mathrm{P} 100 \mathrm{~Pa}$ and at peak flow point, time averaged nasal resistance and integrated nasal patency were measured by a Rhinorheograph MPR-1100 and processed by a computer program, NI-101, in 350 adult patients. The values from the equation $\mathrm{R}=\Delta \mathrm{P} / \dot{\mathrm{V}}$ at $\Delta \mathrm{P} 100 \mathrm{~Pa}$ were slightly lower than those from the same equation at peak flow point or those from the time averaging method. The correlation line between the values of nasal resistance at peak flow point and the time averaged nasal resistance values was very close to the line of identity. No significant correlations were demonstrated between the values from the integrated nasal patency and the values from the other three expressions. We discussed the differences of the results from these expressions in this paper.
\end{abstract}

Key words: nasal resistance, rhinomanometry, nasal patency

\section{緒言}

鼻腔通気度検査法は鼻呼吸動態の客観的評価 法として有用な方法であり，近年科学技術の進 歩により飛躍的な発展を遂げてきた。しかしそ の一方で, 本検查法は本邦でも欧米でも, その 測定方法や表現法の統一が完遂されて打らず, 内外でその標準化が現在も計られている1) 4).

今回我々は，それら解決すべき問題の一つで ある，鼻腔通気の表現法について検討すべく， 鼻腔抵抗の評価法として, 最近, 日本鼻腔通気
度標準化委員会で推奨されている $\Delta \mathrm{P} 100 \mathrm{~Pa}$ の 抵抗值 ${ }^{3)}$ と, 圧流速関係曲線上, ある決められ たポイントを通過する必要がない評価法である peak flow point (以後 PF と略す) の抵抗值 ${ }^{5)}$, 平均值法 (time averaging method) ${ }^{677)}$, 積分值法 (integrated nasal patency) $)^{8)}$ による成績との関 係について比較し, 若干の知見を得たので報告 する.

対象および方法

何らかの鼻症状を訴え, 最近当科を受診した 
成人患者 350 例, 700 側の片側鼻腔抵抗を Active Anterior 法ノズル使用（日本光電社製 鼻腔通気度計 MPR-1100）にて測定し，我々が 開発した，鼻腔通気度解析プログラム NI-101 を用いて， $\Delta \mathrm{P} 100 \mathrm{~Pa}$ と $\mathrm{PF}$ の抵抗值（単位 $\mathrm{Pa} / \mathrm{cm}^{3} / \mathrm{sec}$ ), 平均值法 (単位 $\mathrm{Pa} / \mathrm{cm}^{3} / \mathrm{sec}$ ), 積分值法の成績を算出させた。平均值法におけ る成績は，鼻呼吸中 $30 \mathrm{~Hz}$ の間隔で得られた抵 抗値を平均して計算させた。積分値法は図 1 亿 示すよらに，座標上の圧流速関係曲線の下の面 積を数量的に表現する方法で,

Röhrer の 2 次式

$$
\mathrm{P}=\mathrm{k}_{1} \dot{\mathrm{V}}+\mathrm{K}_{2} \dot{\mathrm{V}}^{2}
$$

から，以下の積分式を作成し算出させた。

$$
\mathrm{INP}=\int_{0}^{\mathrm{P}^{\prime}}\left(-\mathrm{K}_{1}+\sqrt{1 \mathrm{~K}_{1}{ }^{2}+4 \mathrm{~K}_{2} \mathrm{P}}\right) / 2 \mathrm{~K}_{2} \mathrm{dP}
$$$$
\text { (INP : integrated nasal patency) }
$$

これらの成績を互いに対比し，相関式と相関係 数を求めた。な抏，成績は危険率 $5 \%$ 以下の場 合を統計学に有意とした.

\section{成 績}

吸気呼気合わせて 1400 測定值の成績を比較検 討した。なお $\Delta \mathrm{P} 100 \mathrm{~Pa}$ の抵抗值は180側, 吸 呼気合わせて 360 測定值で圧流速関係曲線が $\Delta \mathrm{P} 100 \mathrm{~Pa}$ に到達しておらず，計測不能であっ た。

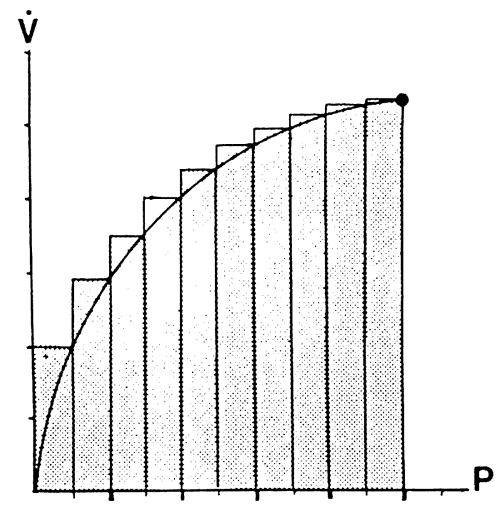

積分值法 $R=\int_{0}^{p^{\prime}}\left(-K_{1}+\sqrt{K_{1}{ }^{2}+4 K_{2} P}\right) / 2 K_{2} d P$ 図 1
まず，現在よく用いられている $\Delta \mathrm{P} 100 \mathrm{~Pa}$ と $\mathrm{PF}$ の抵抗值について比較してみると図 2 のご とく, 関係式は

$$
\begin{aligned}
& \mathrm{Y}=1.58 \mathrm{X}-0.08[\mathrm{Y}: \mathrm{PF}, \mathrm{X}: \Delta \mathrm{P} 100 \mathrm{~Pa}] \\
& (\mathrm{r}=0.93)
\end{aligned}
$$

となり，従来の報告7)9) のよらに $\mathrm{PF}$ が $\Delta \mathrm{P} 100$ $\mathrm{Pa}$ より高值を示す関係であった.

$\Delta \mathrm{P} 100 \mathrm{~Pa}$ と欧米の一部で最近用いられてい る平均值法677) の成績を比較してみると, 図 3 のごとく, 関係式は

$\mathrm{Y}=1.32 \mathrm{X}-0.06[\mathrm{Y}:$ Averaged,

$\mathrm{X}: \Delta \mathrm{P} 100 \mathrm{~Pa}](\mathrm{r}=0.93)$

となり，平均值法は $\Delta \mathrm{P} 100 \mathrm{~Pa}$ より若干高くな る関係を示したが，PF 程ではなかった。

$\mathrm{PF}$ と平均值法では，図 4 のごとく， $\mathrm{Y}=0.80 \mathrm{X}+0.03[\mathrm{Y}:$ Averaged, $\mathrm{X}: \mathrm{FP}]$ $(\mathrm{r}=0.95)$

となり，PF の方が平均值法よりやや高くなる 関係式を示したが，この両者が最も近似した成 績となった。なお，以上の関係式は何れも統計 学的に有意であった。

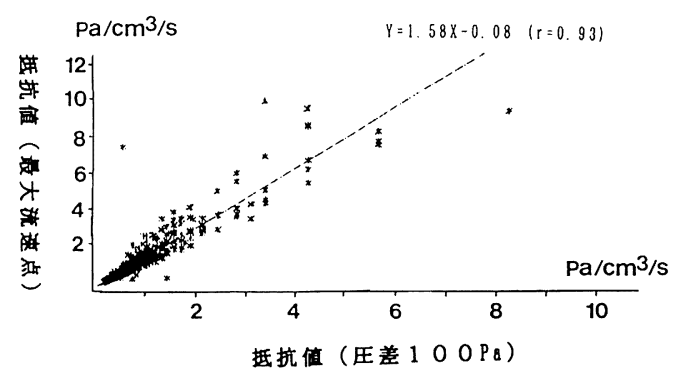

図 2

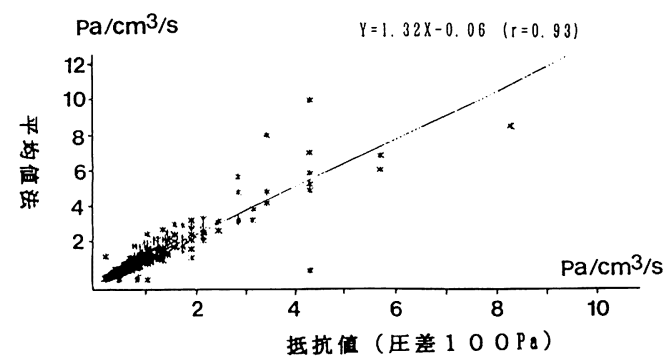

図 3 
次に, 上記 3 者と, 最も新しく報告された積 分值法8)の成績とを比較してみると， $\Delta \mathrm{P} 100$ $\mathrm{Pa}$ とは, 図 5 のごとく,

$\mathrm{Y}=-0.0094 \mathrm{X}+0.05[\mathrm{Y}:$ Integrated,

$\mathrm{X}: \Delta \mathrm{P} 100 \mathrm{~Pa}](\mathrm{r}=-0.26)$

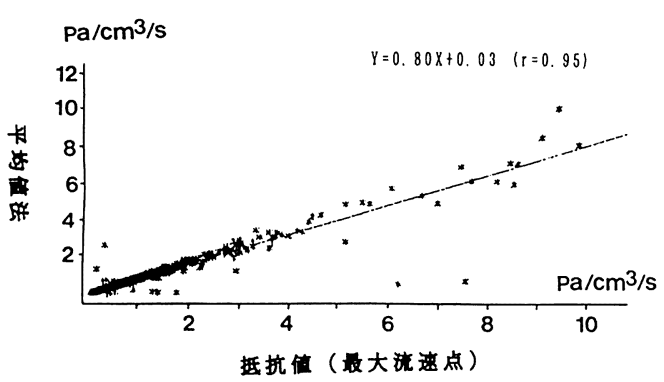

図 4

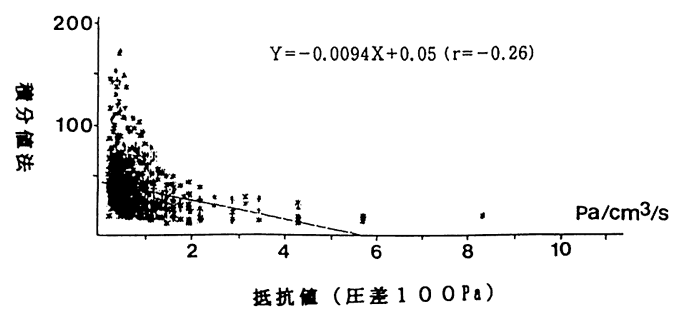

図 5

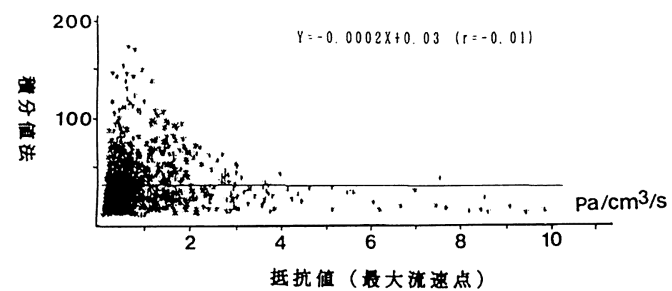

図 6

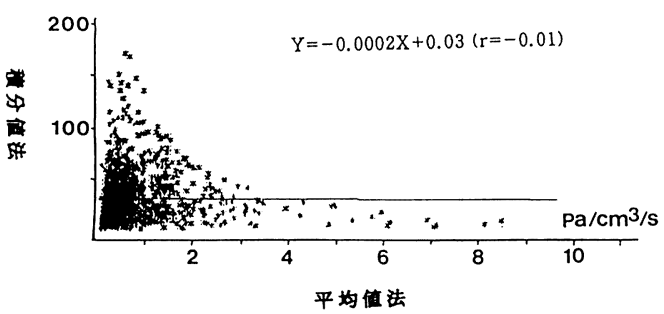

図 7
$\mathrm{PF}$ とは, 図 6 のごとく，

$\mathrm{Y}=-0.0002 \mathrm{X}+0.03[\mathrm{Y}:$ Integrated,

$\mathrm{X}: \mathrm{PF}](\mathrm{r}=-0.01)$

平均值法とは, 図 7 のごとく,

$\mathrm{Y}=-0.0002 \mathrm{X}+0.03[\mathrm{Y}:$ Integrated,

$\mathrm{X}:$ Averaged] $(\mathrm{r}=-0.01)$

となり，何れとも統計学的に有意な相関関係を

示さなかった.

\section{考察}

近年, 鼻腔通気度検査は, 安静鼻呼吸時の鼻 呼吸流速 $(\dot{\mathrm{V}})$ と鼻腔前後圧差 $(\Delta \mathrm{P})$ を同時測定 し，その比から下記の計算式に従い抵抗值 $(\Delta \mathrm{P} / \dot{\mathrm{V}})$ を求め, 表現する方法が一般的となっ てきた。

抵抗 $(\mathrm{R})=$ 圧差 $(\Delta \mathrm{P}) /$ 流速 $(\mathrm{V})$

しかし，この流体の法則に基礎付けられた計 算式は, Reynords 数の小さな層流状態を示す 関係式であり，多くの研究者が報告しているよ らに, 安静鼻呼吸であっても, 実際はそのほと んどが Reynords 数の大きな乱流状態であるこ

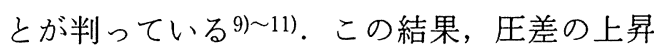
に見合らだけの流速が得られず，圧流速関係線 は曲線となり，必然的にどの時点での抵抗值を 採用するのかといら問題が生じてくることにな る. そのため, それぞれの研究者が様々な評価 点を採用するようになり, 成績の相互比較に障 害を来すようになってきた。

この問題を解決するために, 近年, 国際鼻腔 通気度標準化委員会では圧流速関係曲線上 $\Delta \mathrm{P}$ $150 \mathrm{~Pa}$ の抵抗值を採用するよう推奖している2). しかし，このポイントは我々日本人ばかりか， いくらかの正常欧米成人にとっても，少し高い ことが指摘されている12). Ohki ら ${ }^{13)}$ は日本人 には $\Delta \mathrm{P} 100 \mathrm{~Pa}$ が最も適していると報告し, 日 本鼻腔通気度標準化委員会でもこのポイントの 抵抗值を採用するよう推奖している3)。しかし 実際は，今回の我々の成績のように，片側鼻腔 抵抗でも700側中180側 (26\%) の症例で，その 圧流速関係曲線が $\Delta \mathrm{P} 100 \mathrm{~Pa}$ に到達せず，日本 人にとっても，まだいくらか高いポイントであ 
ることが判明した. もっとも, Naito ら7) の報 告では, 欧米人であっても $24 \%$ の成人でこのポ イントに達していないとされている。

何れにしても，圧流速関係曲線が座標上の， ある決められたポイントを通過しなければなら ないといらことは，自然鼻呼吸に対して，いく らかの負荷的な呼吸を被検者に強いることにな る. そこで, 圧流速関係曲線座標上それらの決 められた通過ポイントを必要としない評価法と して, 従来から PF での抵抗值の有用性が述べ られてきた5)。しかし，PF は同一被検者でも 呼吸毎に変動しており，その不安定性が指摘さ れている. 当教室では測定時に, 落ち着いた鼻 呼吸で, 常時 $\mathrm{PF}$ を安定させるよう被検者に協 力を求め, この指摘から免がれるよう努力して いる.

最近では, $30 \mathrm{~Hz}$ や $50 \mathrm{~Hz}$ で鼻呼吸中の抵抗 值を経時的に平均する平均值法が欧米の一部で 採用されてきている67). この方法から得られ た成績を圧流速関係式として表わすと，

$$
\mathrm{R}=0.83 \Delta \mathrm{P} / \dot{\mathrm{V}}^{1.33}
$$

となり7), これは層流と乱流の中間に当たる混 合流の関係式で, 安静鼻呼吸気流状態のあらゆ る要素（層流〜乱流）を含んだものと考えられ る.しかも $\Delta \mathrm{P} 100 \mathrm{~Pa}, \Delta \mathrm{P} 150 \mathrm{~Pa}, \mathrm{PF}$ など決 められた狭い 1 つのポイントに頼ることもなく, 鼻呼吸全体の流れを抵抗値として表現する優れ た方法の一つである.

さらに, 最近では, 座標上の圧流速関係曲線 の下の部分を数量的に表現するために, 積分し て面積で表わす積分值法が考案されてきた8). この方法も平均值法と同じく, 決められたポイ ントに頼ることなく, 数字としてその程度を表 現できる利点を有している.

この他, 過去には抵抗値といら数字的な表現 ではなく，圧流速関係曲線自体を式としてその 係数で表そうと試みたり ${ }^{14)}$, 乱流係数を関係式 に加えたり915)，座標上に決められた円を描い て, 幾何学的に圧流速関係曲線とその交点を角 度で表わしている研究者もいる16)。
今回我々は, 鼻腔通気の表現法として, 従来 から用いられている $\Delta \mathrm{P} 100 \mathrm{~Pa}$ PF での抵抗 值と, 最近有用とされ, 注目されている平均值 法, 積分值法の成績とを比較検討してみた。 の結果, $\Delta \mathrm{P} 100 \mathrm{~Pa}$ の抵抗值は, $\mathrm{PF}$ p平均值 法の值より過去の報告と同様に7) 低值を示す関 係式となり，PF は平均值法よりやや高めとな るが，この両者はほ湆同等の值を示す関係とな った. その理由として, 鼻呼吸流速曲線の特長 から判るよらに, 時間的に鼻呼吸流速は, 䚾と んぞが PF 周辺に集中して括り，平均值法では, $\mathrm{PF}$ 以外の部分の要素が少ない点が挙げられた。

積分值法は, 今回比較を行なった他のどの方 法とも有意な相関は示さなかった。 その原因と して, 通気良好な場合には $\mathrm{PF}$ は高く, Peak $\Delta \mathrm{P}$ は低くなり, 逆に通気不良の場合は $\mathrm{PF}$ は

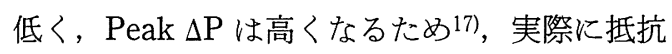
值が大きく異なっても, 圧流速関係曲線の積分 值は図 8 に示すように，両者に注とんど差がな くなるといらことが考えられた，今回の成績か ら，積分値法を鼻腔通気の表現法として用いる 場合には, この点を十分に注意しなければなら ないものと思われた。

今回の我々の研究から, 現在のところ, 圧流 速関係曲線をより理想的に表現している平均値 法が普及していない日本に执いては，日本鼻腔 通気度標準化委員会の推奨する $\Delta \mathrm{P} 100 \mathrm{~Pa}$ の抵 抗值と, $\Delta \mathrm{P} 100 \mathrm{~Pa}$ に達しない場合に備えて, 注意して行なえば平均值法とほぼ同等の值を示
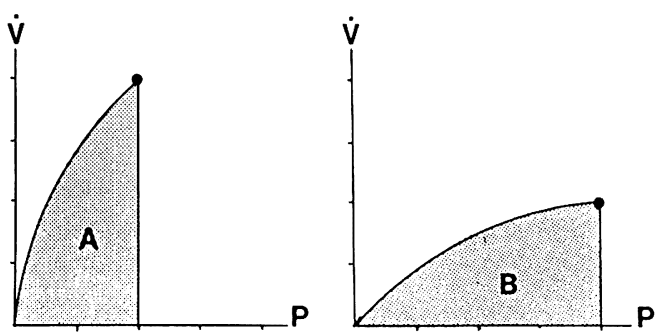

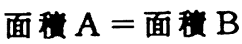

図 8 
す PF の抵抗值を併用するのが，鼻腔抵抗のよ り一般的な用法であるかと思われた。

\section{結語}

鼻腔通気度検査法の表現法として, 従来から 用いられている $\Delta \mathrm{P} 100 \mathrm{~Pa}$ や PF での抵抗值と, 最近有用とされ，注目されている抵抗值の平均 值法や圧流速関係曲線の積分值法の成績とを比 較検討してみた結果，以下の成績を得た。

1. $\mathrm{PF}$ p平均值法の抵抗值は $\Delta \mathrm{P} 100 \mathrm{~Pa}$ の 抵抗值より高くなる相関関係を示し，PF と平 均值法は PF の方が若干高いが，注涪同等の值 を示す関係を示した。

2. 積分值法とは，今回比較した他のどの成 績とも，有意な相関関係を示さなかった。

\section{参考文献}

1) Kern EB : Committee report on standardization of rhinomanometry. Rhinology $19: 231 \sim$ 236, 1981.

2) Clement PAR : Committee report on standardization of rhinomanometry. Rhinology 22 : 151 159, 1984.

3）戸川 清, 岩田重信, 海野徳二, 他 : 鼻腔通気 度測定法の標準化, 鼻腔通気度計の試作と鼻腔 通気度正常值. 鼻腔通気度研究会誌 $1: 1 \sim 13$, 1984.

4) Naito $K$, Iwata $S$, Cole $P$, et al : An international comparison of rhinomanometry between Canada and Japan. Rhinology $29: 287 \sim 294$, 1991.

5）岩田重信, 岩見公晴, 江崎俊夫: 安静呼吸時, 鼻内気流と鼻咽腔圧の相互関係. 耳鼻臨床 70 : 1921 1926, 1977.

6) Cole $P$, Fastag $O$ and Niinimaa $V$ : Computeraided rhinomanometry. Acta Otolaryngol $90:$ 139 142, 1980.

7) Naito $K$, Cole $P$, Chaban $R$, et al : Computer averaged nasal resistance. Rhinology $27: 45$ $\sim 52,1989$.

8) Naitoh $Y$ and Unno $T$ : Numerical expression of nasal resistance regardless of reference point. Rhinology $26: 25,1988$.

9) Naito $K$, Iwata $S$, Kondo $M$, et al : A fundamental study of rhinomanometry and its clinical application to objective evaluation. Auris Nasus Larynx (Tokyo) $16:$ 99 108, 1989.

10) Eichler J and Lenz $H$ : Comparison of different coefficients and units in rhinomanometry. Rhinology 23 : 149 157, 1985.

11) Clement PAR and Hircsh $C$ : Rhinomanometry ; a review. ORL J Otorhinolaryngol Relat Spec 46 : 173 191, 1984.

12) Cole $P$ and Havas TE : Resistance to respiratory airflow of the nasal passage ; comparison between different common methods of calculation. Rhinology 24 : 163 173, 1986.

13) Ohki $M$ and Hasegawa $M$ : Studies of transnasal pressure and airflow values in Japanese population. Rhinology $24: 277 \sim 282$, 1986.

14) Röhrer F : Der Stömungswiderstand in der menschlichen Atemwegen. Pflügers Arch Ges Physiol $162:$ 149 157, 1915.

15) Eichler $F$ and Lenz $H$ : Comparison of different coefficients and units in rhinomanometry. Rhinology $23:$ 149 157, 1985.

16) Broms P, Jonson B and Lamm J : Rhinomaometry II. A system for numerical description of nasal airway resistance. Acta Otolaryngol (Stock) $94:$ 157 168, 1982.

17) Naito $K$, Iwata $S$, Kondo $M$, et al : Human respiratory airflow through an artificial nasal model ; pressure/flow relationship. Auris Nasus Larynx (Tokyo) $16:$ 89 97, 1989.

$$
\left(\begin{array}{l}
\text { 別刷請求先 : 内藤健晴 } \\
\text { 干 } 470-11 \text { 豊明市沓掛町田楽ヶ窪1-98 } \\
\text { 藤田保健衛生大学医学部耳鼻咽喉科学教室 }
\end{array}\right)
$$

